\title{
Evaluation of Chiral Recognition \\ Characteristics of Metal and Proton Complexes of di-o-Benzoyl-Tartaric Acid Dibutyl Ester and L-Tryptophan in the Gas Phase
}

\author{
Hao-Jie Lu and Yin-Long Guo \\ Shanghai Institute of Organic Chemistry, Chinese Academy of Sciences, Shanghai, People's Republic of China
}

\begin{abstract}
Chiral recognition of di-o-benzoyl-tartaric acid dibutyl ester $(\mathrm{T})$ was achieved in the gas phase by electrospray ionization Fourier transform ion cyclotron resonance mass spectrometry. In this method two divalent transition metal cations, zinc(II) and copper(II), were used as binding metal ions, and L-tryptophan (A) was used as a chiral reference. Multimeric complexes were readily formed by electrospray ionization of a methanol:water (50:50) solution containing metal ion, L-tryptophan and T. These multimeric complexes included singly charged protonated dimeric $[\mathrm{TAH}]^{+}$, doubly charged copper(II) bound tetrameric $[\mathrm{TACu}-\mathrm{H}]_{2}^{2+}$ and doubly charged zinc(II) bound tetrameric $[\mathrm{TAZn}-\mathrm{H}]_{2}^{2+}$, together with other complexes. The massselected complex, i.e., $[\mathrm{TAH}]^{+},[\mathrm{TACu}-\mathrm{H}]_{2}^{2+}$ and $[\mathrm{TAZn}-\mathrm{H}]_{2}^{2+}$, was used to acquire the second stage mass spectra. The chiral recognition capability of these three complexes was evaluated using the abundance ratios of daughter ion to parent ion. A high degree of chiral recognition ability was observed in $[\mathrm{TACu}-\mathrm{H}]_{2}^{2+}$ and $[\mathrm{TAZn}-\mathrm{H}]_{2}^{2+}$. It was found that the type of binding ion played an important role in the chiral recognition. Different binding ions exhibited distinctive dissociation pathways and unique chiral recognition characteristics. The present method is based not only on whole-molecule loss but also on fractional-molecule loss. In addition, the reproducibility of the chiral recognition method was confirmed by several determinations of the abundance ratios of daughter ion to parent ion with a fixed activation energy and with five different activation energies. It was also shown that this chiral recognition method can tolerate acid interference. (J Am Soc Mass Spectrom 2003, 14, 571-580) ( 2003 American Society for Mass Spectrometry
\end{abstract}

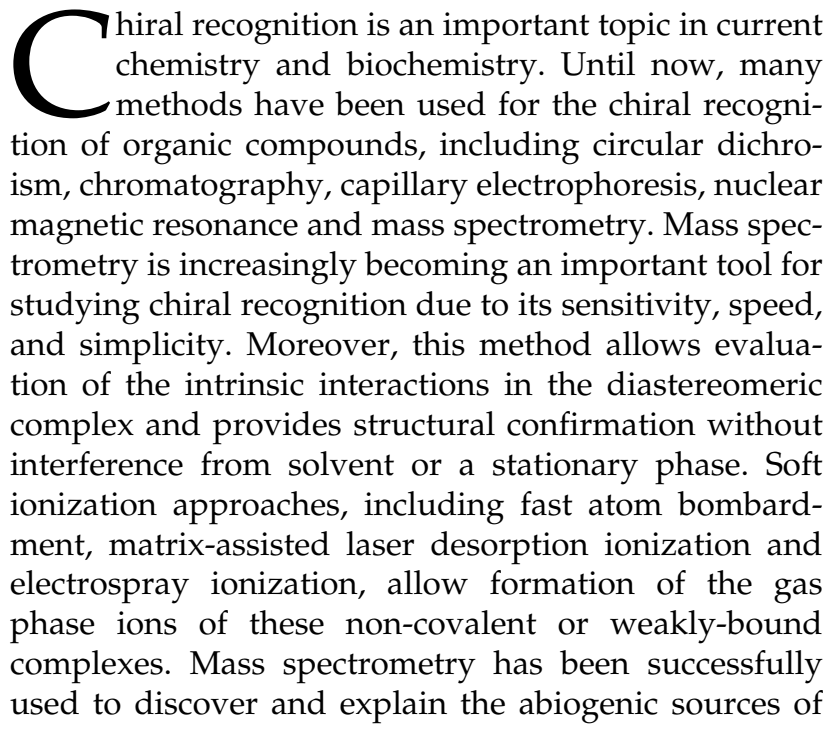

Published online April 24, 2003

Address reprint requests to Dr. Y.-L. Guo, Shanghai Institute of Organic Chemistry, Chinese Academy of Sciences, Shanghai 200032, People's Republic of China. E-mail: ylguo@pub.sioc.ac.cn homochirality that might be an important step towards the explanation of the origin of life [1, 2]. Significant progress has been made on chiral recognition based exclusively on mass spectrometry since the first published paper [3-5]. Many elegant methods have been developed, such as: (1) Discriminating the intensities of the pair of diastereomeric complexes in one stage mass spectra based on their different stabilities, including the enantiomer guest or host labeled method [6-17]. This method has been used to rapidly screen the chiral discrimination abilities in combinatorial chemistry because of its simplicity and speed, however, the energy difference between the pair of diastereomeric complexes must be sufficiently large [6, 7]. (2) Discriminating the abundance ratios of daughter ion to parent ion after the mass-selected diastereomeric complexes are fragmented in second stage mass spectra [18-20]. (3) Discriminating the abundance ratios of two daughter ions (based on two competitive dissociation pathways) after the mass-selected diastereomeric complexes are fragmented in second stage mass spectra. This method is popularly known as the kinetic method, and has gained much attention recently [21-26]. However the 
"kinetic method" has a rigorous condition that the target compound and the chiral reference must be both protonated or cationized and must have equal detection efficiencies. Therefore, the structure of the chiral reference must be similar to that of the target compound. (4) Discriminating the intensities of product or reactant complexes in second stage mass spectra based on the different ion/molecule reaction rates of the pair of diastereomeric complexes [27, 28]. All these methods employ a chiral host molecule or an optically pure reagent to associate with the target compound forming a pair of diastereomeric complexes. Many kinds of macrocyclic compounds have already been used as chiral references in mass spectrometry [8-12, 27, 28]. The metal binding complexes of natural chiral amino acids are commonly utilized chiral selectors [21, 22]. It has been shown that these chiral amino acids with an aromatic side chain provide the greatest chiral distinction [19-22]. Furthermore, the electron-donating nitrogen in Trp and His appears to be important for substantial chiral discrimination [19]. The metal ions of lithium, cobalt, antimony and copper have been used to assist the chiral reference in achieving chiral recognition [13, 21-25]. Copper ion is the most utilized metal ion and the characteristics of copper associated complexes have also been studied [29-33]. Recently, zinc ion has also been used as a binding metal ion to effect good chiral recognition of sugars [34]. Dialkyltartrates were the first class of model compounds selected as targets to study chiral recognition by mass spectrometry [3]. Since that time tartaric acid and its derivatives were used frequently to study their chirality in the gas phase [35-42]. Herein, di-o-benzoyl-tartaric acid dibutyl ester (T) is selected as a target to study its chirality using Ltryptophan (A) as a chiral reference and zinc(II) or copper(II) as an auxiliary metal ion by electrospray ionization Fourier transform ion cyclotron resonance mass spectrometry (ESI-FTMS). When the solution of T with a transition metal salt and L-tryptophan undergoes electrospray ionization, many multimeric complexes are efficiently generated, such as singly charged copper(II) bound trimeric $\left[\mathrm{TA}_{2} \mathrm{Cu}-\mathrm{H}\right]^{+}$, singly charged protonated dimeric $[\mathrm{TAH}]^{+}$, doubly charged copper(II) bound tetrameric $[\mathrm{TACu}-\mathrm{H}]_{2}^{2+}$ and $\left[\mathrm{T}_{3} \mathrm{ACu}\right]^{2+}$, doubly charged zinc(II) bound tetrameric $[\mathrm{TAZn}-\mathrm{H}]_{2}^{2+}$ and $\left[\mathrm{T}_{3} \mathrm{AZn}\right]^{2+}$, doubly charged zinc(II) bound pentameric $\left[\mathrm{T}_{3} \mathrm{~A}_{2} \mathrm{Zn}\right]^{2+},\left[\mathrm{T}_{2} \mathrm{~A}_{3} \mathrm{Zn}\right]^{2+}$ and $\left[\mathrm{T}_{4} \mathrm{AZn}\right]^{2+}$, and even doubly charged zinc(II) bound hexameric $\left[\mathrm{T}_{3} \mathrm{~A}_{3} \mathrm{Zn}\right]^{2+}$. Three types of multimeric complexes, i.e., $[\mathrm{TAH}]^{+}$, $[\mathrm{TACu}-\mathrm{H}]_{2}^{2+}$ and $[\mathrm{TAZn}-\mathrm{H}]_{2}^{2+}$, are then selected to obtain tandem mass spectra. Both $[\mathrm{TACu}-\mathrm{H}]_{2}^{2+}$ and $[\mathrm{TAZn}-\mathrm{H}]_{2}^{2+}$ are novel complexes; in these tandem mass spectrometry experiments, both $[\mathrm{TACu}-\mathrm{H}]_{2}^{2+}$ and $[\mathrm{TAZn}-\mathrm{H}]_{2}^{2+}$ generate special and discriminative fragments, respectively, depending strongly on both the stereo configuration of $\mathrm{T}$ and the type of the binding ion. A high degree of chiral recognition capability is demonstrated in these two pairs of diastereomeric complexes. In addition the reproducibility of the method is confirmed by several determinations of the abundance ratios of daughter ion to parent ion under a fixed activation energy and under five different activation energies. The stability of the method is also studied by adding acetic acid to the mixed solution. Finally, it is worth noting that the present method achieves chiral recognition based on not only whole-molecule loss but also fractional-molecule loss; the latter is rarely reported.

\section{Experimental}

\section{Instrumentation and Methods}

All MS and tandem MS experiments were carried out at Bruker Daltonics (Billerica, MA) using an APEX III ${ }^{\mathrm{TM}}$ ESI-FTMS equipped with a 7.0 Tesla shielded superconducting magnet. The vacuum was maintained by two systems of rotary vacuum pumps followed by turbomolecular pumps in two different regions: ion source (maintained $\sim 5.0 \times 10^{-7}$ torr) and cell region (maintained $\sim 4.0 \times 10^{-10}$ torr). The ions were focused through the ion transfer region by the RF-only hexapole ion guide and were transferred to the cell for trapping and detection. All the parameters of the ESI source, ion transfer, and cell were optimized for sensitivity. The main parameters were: The capillary and end plate voltages were -4576 and $-4056 \mathrm{~V}$, respectively. Dry gas and nebulization gas temperatures were $116^{\circ} \mathrm{C}$ and $300^{\circ} \mathrm{C}$, respectively. The ESI generated ions were accumulated in a hexapole for $0.5 \mathrm{~s}$ before being transferred to the cell. The cell trapping potential on the front plate (PV1) was $0.87 \mathrm{~V}$ and the potential on the back plate (PV2) was $1.08 \mathrm{~V}$ with the potential difference between the sidekick electrodes (DEV2) of $-8.80 \mathrm{~V}$. For the tandem MS experiments the mass isolation and activation were performed with the isolation sweep attenuation/isolation pulse length of 12 $\mathrm{dB} / 1 \mathrm{~ms}$ and activation attenuation/activation pulse length of $30 \mathrm{~dB} / 1 \mathrm{~s}$, respectively (unless specified otherwise). When fragmentation of the multimeric complexes was studied, argon gas was introduced into the cell using a variable leak valve (a pulse length of $1 \mathrm{~ms}$ ) and maintained at $\sim 5 \times 10^{-8}$ torr. The postive ion mode was used to acquire the spectra with broadband detection (20 scans per experiment each) from 100 to $1500 \mathrm{Da}$ using $256 \mathrm{~K}$ data points. All experimental sequences including scan accumulation and data processing were performed with XMASS 6.0.0 software on a DELL computer with $256 \mathrm{MB}$ RAM, 40 GB harddrive. The samples were injected at a flow rate of $5 \mu \mathrm{L} / \mathrm{min}$ using a syringe pump. The instrument was calibrated externally with a 50:50 water/methanol solution of PEG-400.

\section{Preparation of the Samples}

The enantiomerically pure L- and D-T were obtained from Shanghai Institute of Organic Chemistry, and were identified by IR spectra, CD, ${ }^{1} \mathrm{H}$ NMR, ${ }^{13} \mathrm{C}$ NMR and high resolution MS. Anhydrous $\mathrm{ZnSO}_{4}$ and anhydrous $\mathrm{CuSO}_{4}$ were purchased from Shanghai Institute of 

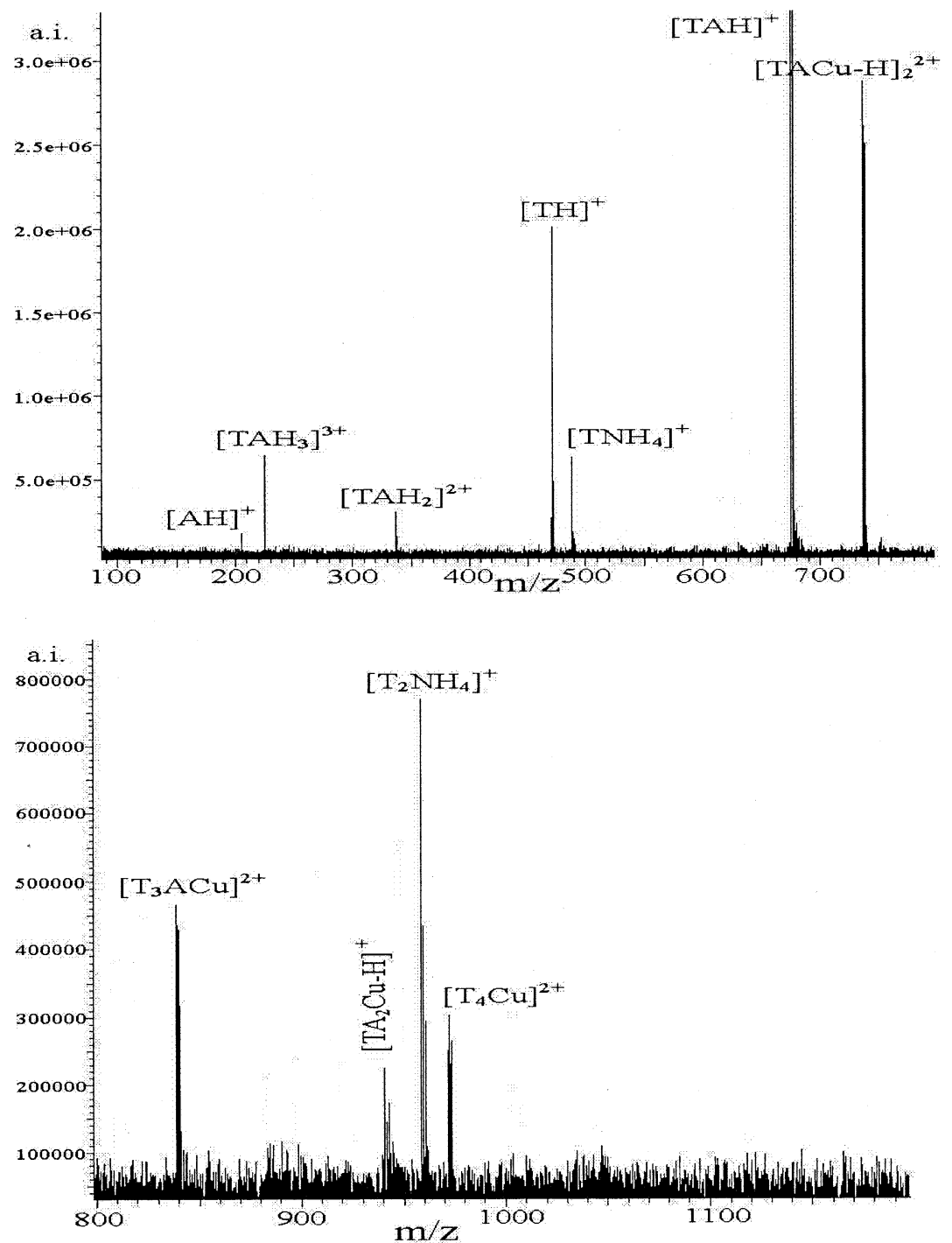

Figure 1. ESI-FTMS spectrum of solutions of 50:50 water:methanol containing copper(II) salt, L-tryptophan, and L-T. The mass spectrum is divided into two parts, the first part is from 100 to 800 $\mathrm{Da}$, and the second part is from 800 to $1200 \mathrm{Da}$ with the y-axis expanded approximately five times.

Science and Technology as analytically pure reagents; they were used without further purification. All the above compounds, as well as L-tryptophan (purchased from Sigma, St. Louis, MO) were dissolved in 50:50 (vol/vol) deionized water/methanol, respectively. The gas phase multimeric complexes were generated by electrospray ionziation of the solutions containing $\mathrm{Zn}^{2+}$ or $\mathrm{Cu}^{2+}$, L-tryptophan and enantiomerically pure T, 3.3 $\times 10^{-6} \mathrm{~mol} / \mathrm{mL}$ each.

\section{Results and Discussion}

\section{Forming Multimeric Complexes Containing Different Binding Ions}

The target compound of $\mathrm{T}$ was studied in two combinations with L-tryptophan, i.e., DL (heterochiral) and LL (homochiral). Therefore, four types of solutions, i.e., $\left(\mathrm{Zn}^{2+}, \mathrm{L}-\right.$ tryptophan, and $\left.\mathrm{L}-\mathrm{T}\right),\left(\mathrm{Zn}^{2+}\right.$, L-tryptophan, and
D-T), $\left(\mathrm{Cu}^{2+}\right.$, L-tryptophan, and L-T) and $\left(\mathrm{Cu}^{2+}\right.$, L-tryptophan, and D-T), were chosen to efficiently generate different kinds of multimeric complexes in the single stage mass spectra. Typical mass spectra are illustrated in Figure 1 (electrospray ionization of $\mathrm{Cu}^{2+}$, L-tryptophan, and L-T) and Figure 2 (electrospray ionization of $\mathrm{Zn}^{2+}$, L-tryptophan and D-T). It was easy to find the following multimeric complexes, i.e., singly charged copper(II) bound trimeric $\left[\mathrm{TA}_{2} \mathrm{Cu}-\mathrm{H}\right]^{+}$, doubly charged copper(II) bound tetrameric $[\mathrm{TACu}-\mathrm{H}]_{2}^{2+}$, and $\left[\mathrm{T}_{3} \mathrm{ACu}\right]^{2+}$ in Figure 1, doubly charged zinc(II) bound tetrameric $[\mathrm{TAZn}-\mathrm{H}]_{2}^{2+}$ and $\left[\mathrm{T}_{3} \mathrm{AZn}\right]^{2+}$, doubly charged zinc(II) bound pentameric $\left[\mathrm{T}_{3} \mathrm{~A}_{2} \mathrm{Zn}\right]^{2+},\left[\mathrm{T}_{2} \mathrm{~A}_{3} \mathrm{Zn}\right]^{2+}$ and $\left[\mathrm{T}_{4} \mathrm{AZn}\right]^{2+}$, even doubly charged zinc(II) bound hexameric $\left[\mathrm{T}_{3} \mathrm{~A}_{3} \mathrm{Zn}\right]^{2+}$ in Figure 2, and singly charged protonated dimeric $[\mathrm{TAH}]^{+}$, doubly charged protonated dimeric $\left[\mathrm{TAH}_{2}\right]^{2+}$ and trebly charged protonated dimeric $\left[\mathrm{TAH}_{3}\right]^{3+}$ in both Figure 1 and Figure 2 . The types and masses of all generated ions are listed in 

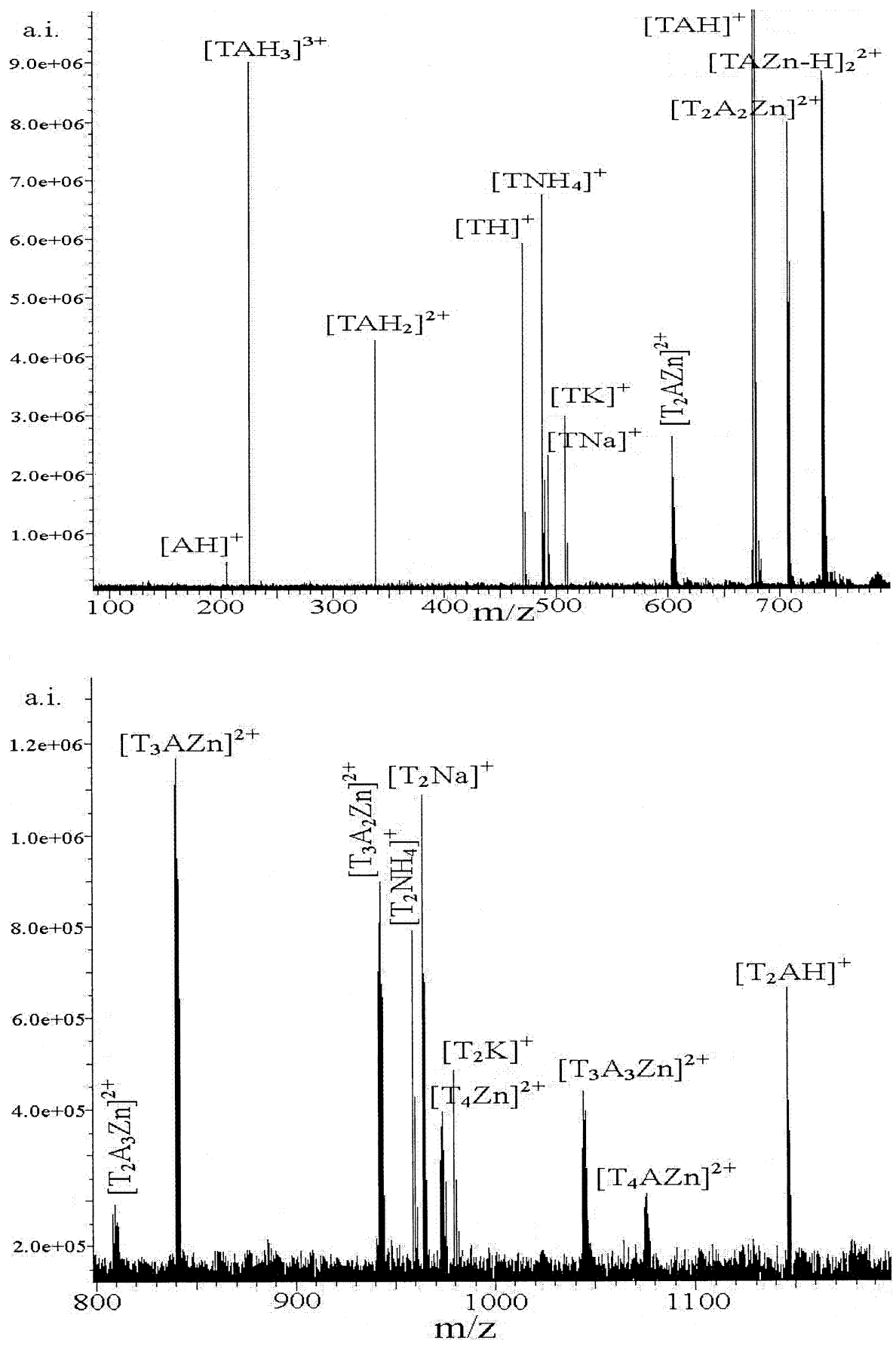

Figure 2. ESI-FTMS spectrum of solutions of 50:50 water:methanol containing zinc(II) salt, Ltryptophan, and L-T. The mass spectrum is divided into two parts, the first part is from 100 to $800 \mathrm{Da}$, and the second part is from 800 to 1200 Da with the y-axis expanded approximately five times.

Table 1. The mass assignments were made with both $\mathrm{m} / \mathrm{z}$ measurements and isotopic distributions. Complexes containing $\mathrm{Zn}^{2+}$ or $\mathrm{Cu}^{2+}$ were easily identified due to the special isotopic characteristics of zinc and copper. When $\mathrm{Zn}^{2+}$ was used as the binding ion more types of multimeric complexes were generated (shown in Table 1). The peak abundances in the single stage mass spectra showed no measurable differences among the diastereomeric complexes containing $\mathrm{H}^{+}, \mathrm{Zn}^{2+}$, or $\mathrm{Cu}^{2+}$ as binding ions. This result indicated that the difference in stability between the homo- and the heterochiral multimeric complexes was not large. Therefore, tandem mass spectrometry experiments were utilized to study the chirality of T.

\section{Dissociating Multimeric Complexes Containing Different Binding Ions}

In the first instance, the pair of diastereomeric complexes of $[\mathrm{TAH}]^{+}$were mass selected due to the high 
Table 1. Type and mass of the ions generated in Figure 1 and Figure 2

\begin{tabular}{|c|c|c|c|c|}
\hline \multirow[b]{2}{*}{ Type of lons } & \multicolumn{2}{|c|}{ Ions in Figure 1} & \multicolumn{2}{|c|}{ Ions in Figure 2} \\
\hline & Ion & Mass & Ion & $\operatorname{Mass}(m / z)$ \\
\hline$[\mathrm{AH}]^{+}$ & {$[\mathrm{AH}]^{+}$} & 205.12 & {$[\mathrm{AH}]^{+}$} & 205.12 \\
\hline$\left[\mathrm{TAH}_{3}\right]^{3+}$ & {$\left[\mathrm{TAH}_{3}\right]^{3+}$} & 225.15 & {$\left[\mathrm{TAH}_{3}\right]^{3+}$} & 225.15 \\
\hline$\left[\mathrm{TAH}_{2}\right]^{2+}$ & {$\left[\mathrm{TAH}_{2}\right]^{2+}$} & 337.69 & {$\left[\mathrm{TAH}_{2}\right]^{2+}$} & 337.69 \\
\hline$[\mathrm{TH}]^{+}$ & {$[\mathrm{TH}]^{+}$} & 471.28 & {$[\mathrm{TH}]^{+}$} & 471.28 \\
\hline$\left[\mathrm{TNH}_{4}\right]^{+}$ & {$\left[\mathrm{TNH}_{4}\right]^{+}$} & 448.31 & {$\left[\mathrm{TNH}_{4}\right]^{+}$} & 488.31 \\
\hline$[\mathrm{TNa}]^{+}$ & $\mathrm{NON}^{\mathrm{a}}$ & & {$[\mathrm{TNa}]^{+}$} & 493.27 \\
\hline$[\mathrm{TK}]^{+}$ & NON & & {$[\mathrm{TK}]^{+}$} & 509.25 \\
\hline$\left[\mathrm{T}_{2} \mathrm{AM}\right]^{2+}$ & NON & & {$\left[\mathrm{T}_{2} \mathrm{AZn}\right]^{2+}$} & 604.32 \\
\hline$[\mathrm{TAH}]^{+}$ & {$[\mathrm{TAH}]^{+}$} & 675.41 & {$[\mathrm{TAH}]^{+}$} & 675.42 \\
\hline$\left[\mathrm{T}_{2} \mathrm{~A}_{2} \mathrm{M}\right]^{2+}$ & NON & & {$\left[\mathrm{T}_{2} \mathrm{~A}_{2} \mathrm{Zn}\right]^{2+}$} & 706.40 \\
\hline$[\text { TAM-H }]_{2}{ }^{2+}$ & {$[\mathrm{TACu}-\mathrm{H}]_{2}^{2+}$} & 736.37 & {$[\mathrm{TAZn}-\mathrm{H}]_{2}^{2+}$} & 737.42 \\
\hline$\left[\mathrm{T}_{2} \mathrm{~A}_{3} \mathrm{M}\right]^{2+}$ & NON & & {$\left[\mathrm{T}_{2} \mathrm{~A}_{3} \mathrm{Zn}\right]^{2+}$} & 808.47 \\
\hline$\left[\mathrm{T}_{3} \mathrm{AM}\right]^{2+}$ & {$\left[\mathrm{T}_{3} \mathrm{ACu}\right]^{2+}$} & 838.98 & {$\left[\mathrm{~T}_{3} \mathrm{AZn}\right]^{2+}$} & 839.99 \\
\hline$\left[\mathrm{TA}_{2} \mathrm{M}-\mathrm{H}\right]^{+}$ & {$\left[\mathrm{TA}_{2} \mathrm{Cu}-\mathrm{H}\right]^{+}$} & 940.51 & NON & \\
\hline$\left[\mathrm{T}_{3} \mathrm{~A}_{2} \mathrm{M}\right]^{2+}$ & NON & & {$\left[\mathrm{T}_{3} \mathrm{~A}_{2} \mathrm{Zn}\right]^{2+}$} & 941.58 \\
\hline$\left[\mathrm{T}_{2} \mathrm{NH}_{4}\right]^{+}$ & {$\left[\mathrm{T}_{2} \mathrm{NH}_{4}\right]^{+}$} & 958.65 & {$\left[\mathrm{~T}_{2} \mathrm{NH}_{4}\right]^{+}$} & 958.65 \\
\hline$\left[\mathrm{T}_{2} \mathrm{Na}\right]^{+}$ & NON & & {$\left[\mathrm{T}_{2} \mathrm{Na}\right]^{+}$} & 963.62 \\
\hline$\left[\mathrm{T}_{4} \mathrm{M}\right]^{2+}$ & {$\left[\mathrm{T}_{4} \mathrm{Cu}\right]^{2+}$} & 927.08 & {$\left[\mathrm{~T}_{4} \mathrm{Zn}\right]^{2+}$} & 973.10 \\
\hline$\left[\mathrm{T}_{2} \mathrm{~K}\right]^{+}$ & NON & & {$\left[\mathrm{T}_{2} \mathrm{~K}\right]^{+}$} & 979.60 \\
\hline$\left[\mathrm{T}_{3} \mathrm{~A}_{3} \mathrm{M}\right]^{2+}$ & NON & & {$\left[\mathrm{T}_{3} \mathrm{~A}_{3} \mathrm{Zn}\right]^{2+}$} & 1043.66 \\
\hline$\left[\mathrm{T}_{4} \mathrm{AM}\right]^{2+}$ & NON & & {$\left[\mathrm{T}_{4} \mathrm{Azn}\right]^{2+}$} & 1074.69 \\
\hline$\left[\mathrm{T}_{2} \mathrm{AH}\right]^{+}$ & NON & & {$\left[\mathrm{T}_{2} \mathrm{AH}\right]^{+}$} & 1145.79 \\
\hline
\end{tabular}

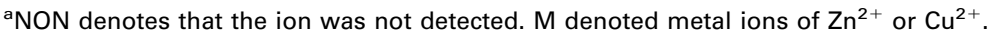

sensitivity and intensity. The product ion spectra showed that only two daughter ions were generated, one was $[\mathrm{AH}]^{+}$formed simply by the loss of a neutral ligand of $\mathrm{T}$, the other was $\left[\mathrm{AH}-\mathrm{NH}_{3}\right]^{+}(\mathrm{m} / \mathrm{z}$ 188.09) formed by the loss of both a neutral ligand of $\mathrm{T}$ and $\mathrm{NH}_{3}$. The corresponding tandem mass spectra are shown in Figure 3. The relative abundance ratio $\mathrm{R}$ was given by $\mathrm{R}=[\mathrm{D}]^{+} /[\mathrm{TAH}]^{+}$(here $[\mathrm{D}]^{+}$denoted the intensity of daughter ions). In these experiments $\mathrm{T}$ was enantiomerically pure, therefore, $R$ became $R_{L}$ for $L-T$ or $R_{D}$ for $D-T$, and the chiral selectivity $R_{\text {chiral }}$ is given by $R_{\text {chiral }}=R_{L} / R_{D}$ as proposed in the literature [20]. The value of $R_{\text {chiral }}$ was close to unity $\left(R_{\text {chiral }}=0.95\right)$ using $[\mathrm{AH}]^{+}$as a reference ion. When $\left[\mathrm{AH}-\mathrm{NH}_{3}\right]^{+}$was used as a reference ion, the result was similar with $R_{\text {chiral }}=1.03$. The value of $R_{\text {chiral }}$ reflects the degree of chiral distinction. The further that the $R_{\text {chiral }}$ value is from unity, the higher the degree of chiral recognition. Chiral discrimination can be recognized by a value of $\mathrm{R}_{\text {chiral }}$ larger than 1.1 or smaller than 0.9 . On this basis, the data from this experiment showed that almost no chiral discrimination was found because of the small energy difference between the pair of the diastereomeric complexes $[\mathrm{TAH}]^{+}$. Therefore, metal binding complexes were mass selected as parent ions to achieve chiral recognition.

Fortunately, several complexes included both ligands $\mathrm{A}$ and $\mathrm{T}$ which possessed the potential of chiral discrimation. The ion [TAM-H $]_{2}^{2+}$ was selected since it was generated with $\mathrm{Cu}^{2+}$ or $\mathrm{Zn}^{2+}$ as the binding ion, and because of its novel formation and its relatively high sensitivity. To the best of our knowledge, such a complex has not been reported for the study of chiral
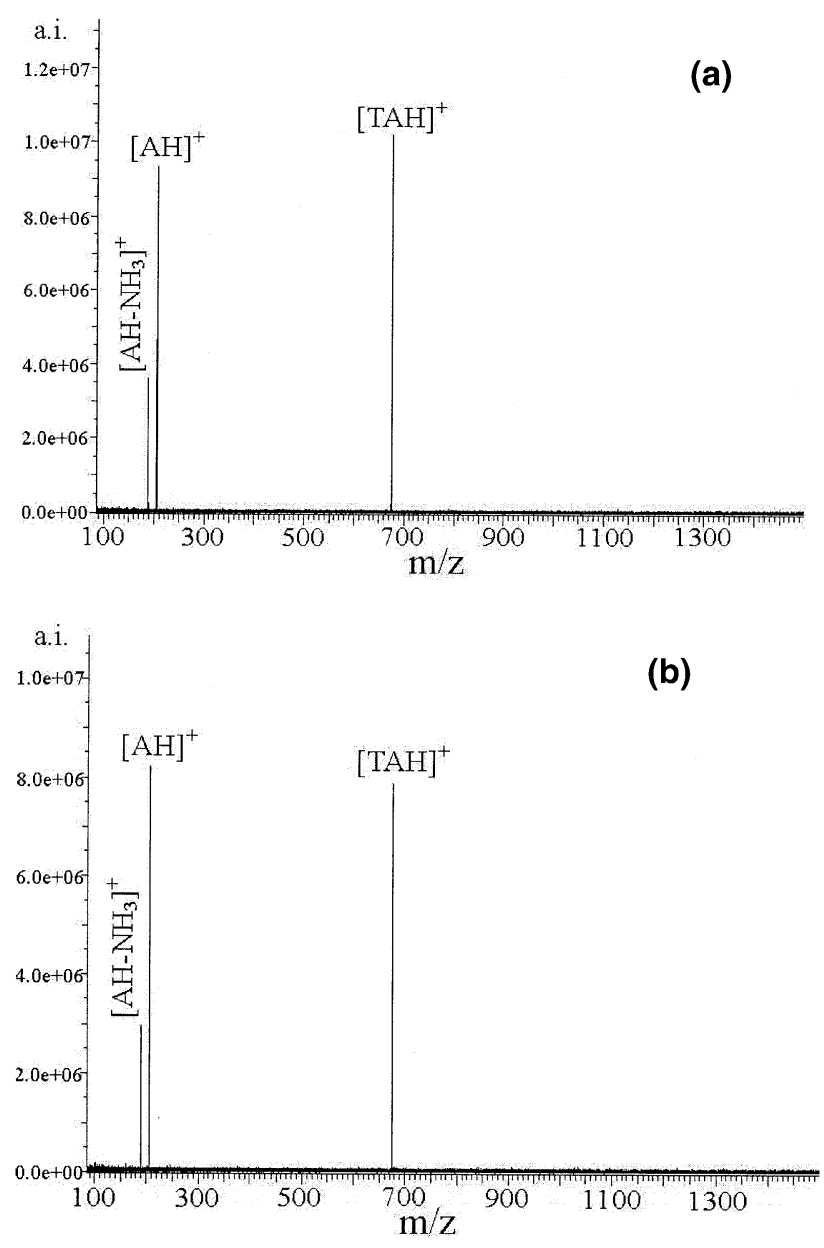

Figure 3. ESI-FTMS/MS spectra of $[\mathrm{TAH}]^{+}$containing (a) L-T or (b) D-T. 

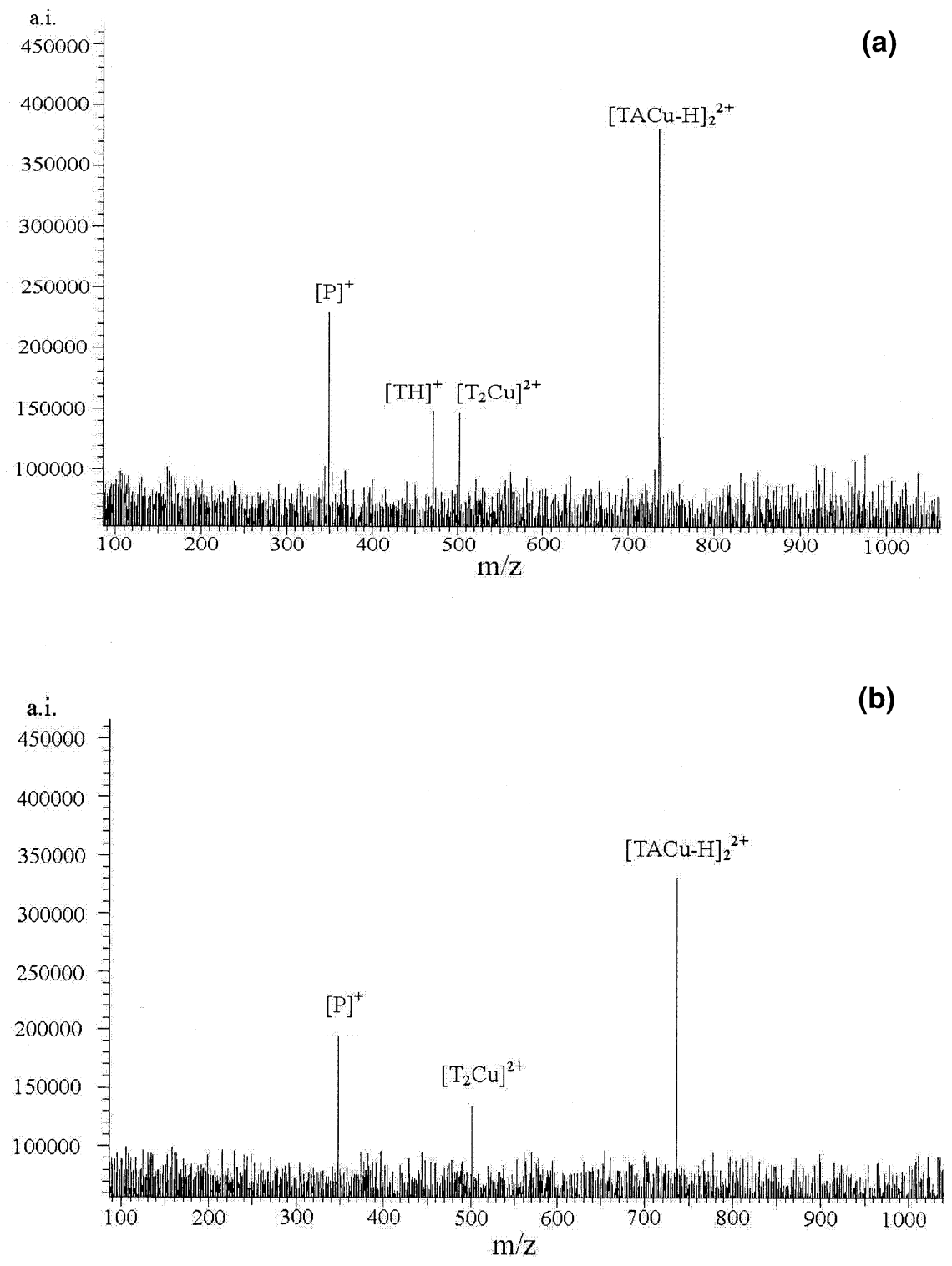

Figure 4. ESI-FTMS/MS spectra of $[\mathrm{TACu}-\mathrm{H}]_{2}^{2+}$ containing (a) L-T or (b) D-T

recognition. The pair of diastereomeric complexes of $[\mathrm{TACu}-\mathrm{H}]_{2}^{2+}$ produced different fragmentation patterns, which showed a high degree of chiral discrimination depending strongly on the stereo configuration of $\mathrm{T}$ (the tandem mass spectra are shown in Figure 4). For $[\mathrm{TACu}-\mathrm{H}]_{2}^{2+}$ containing D-T, only two daughter ions were produced, one was doubly charged $\mathrm{Cu}^{2+}$ binding dimeric ion $\left[\mathrm{T}_{2} \mathrm{Cu}\right]^{2+}$ formed by the loss of a neutral complex of $\left[\mathrm{A}_{2} \mathrm{Cu}-\mathrm{H}_{2}\right]$, the other was a protonated fragment ion $[\mathrm{P}]^{+}$(a fragment of $\mathrm{T}$ by the loss of benzoic acid, $m / z$ 349.20). In contrast, for $[\mathrm{TACu}-\mathrm{H}]_{2}^{2+}$ containing L-T, another daughter ion was generated which was singly charged protonated monomeric ion $[\mathrm{TH}]^{+}$in addition to $\left[\mathrm{T}_{2} \mathrm{Cu}\right]^{2+}$ and $[\mathrm{P}]^{+}$. However, chiral discrimination was not achieved when $[\mathrm{P}]^{+}$or $\left[\mathrm{T}_{2} \mathrm{Cu}\right]^{2+}$ was used as a reference ion $\left(R_{\text {chiral }}=1.01\right.$ for the former and $R_{\text {chiral }}=0.93$ for the latter). Fortunately, chiral recognition was achieved with an infinite value of $R_{\text {chiral }}$ using $[\mathrm{TH}]^{+}$as a reference ion. Therefore dramatic chiral recognition ability was demonstrated by this unique ion formed only by dissociating $[\mathrm{TACu}-\mathrm{H}]_{2}^{2+}$ containing L-T. This phenomenon was very attractive and interesting so that further studies were carried out by selecting $[\mathrm{TAZn}-\mathrm{H}]_{2}^{2+}$ as another pair of diastereomeric complexes.

As expected, two familiar daughter ions of $\left[\mathrm{T}_{2} \mathrm{Zn}\right]^{2+}$ and $[\mathrm{P}]^{+}$were produced in the tandem mass spectra. However, it was surprising that only these two daughter ions were produced for $[\mathrm{TAZn}-\mathrm{H}]_{2}^{2+}$ containing L-T. In contrast, another daughter ion was produced for $[\mathrm{TAZn}-\mathrm{H}]_{2}^{2+}$ containing D-T in addition to $\left[\mathrm{T}_{2} \mathrm{Zn}\right]^{2+}$ and $[\mathrm{P}]^{+}$. Furthermore, the third daughter ion was $[\mathrm{AH}]^{+}$ instead of $[\mathrm{TH}]^{+}$. In contrast to the case of $\mathrm{Cu}^{2+}, \mathrm{Zn}^{2+}$ as the binding ion resulted in a high degree of chiral recognition ability by using each daughter ion as a reference ion $\left(R_{\text {chiral }}=1.98, R_{\text {chiral }}=1.90\right.$ and $R_{\text {chiral }}=0$ 

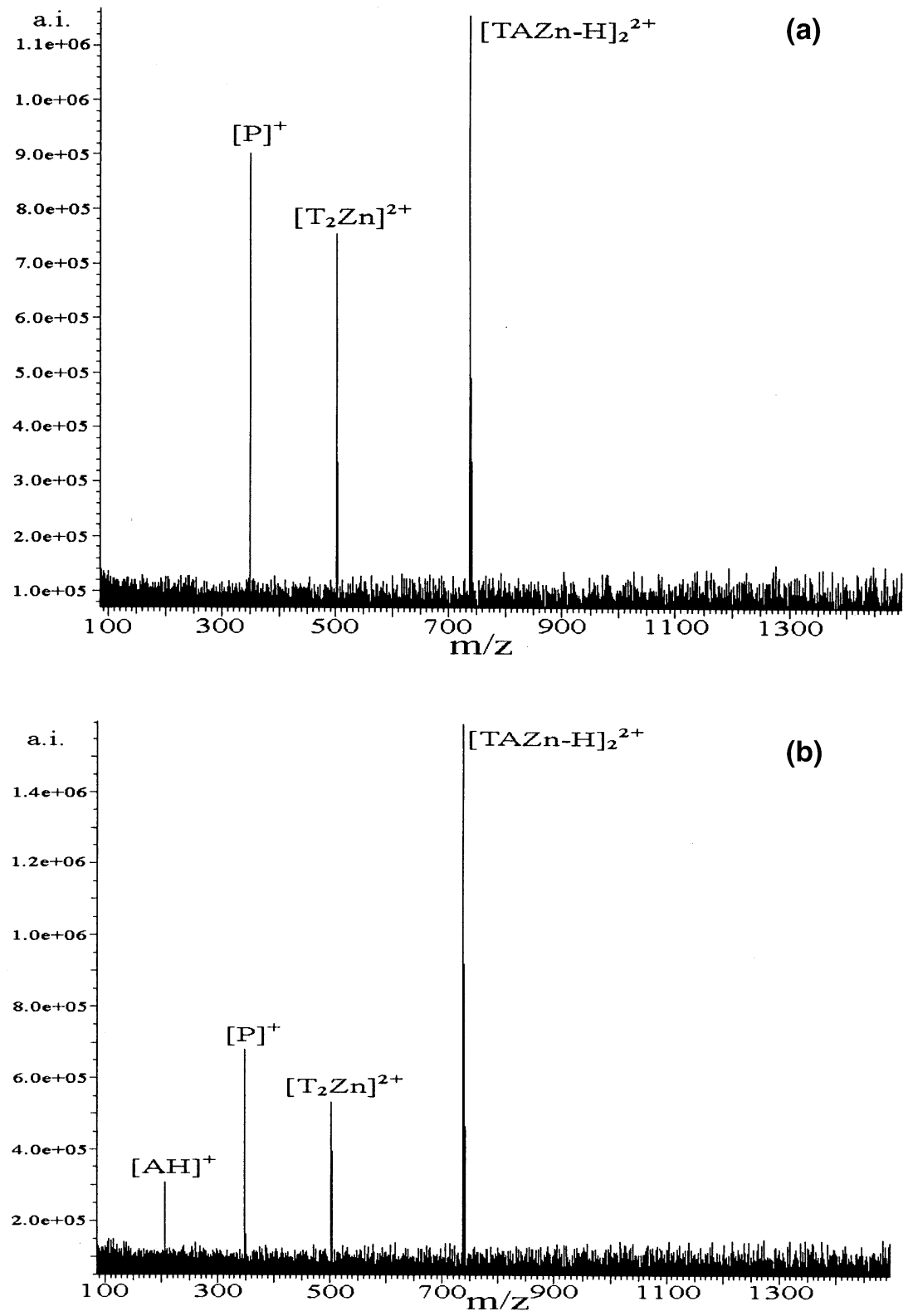

Figure 5. ESI-FTMS/MS spectra of $[\mathrm{TAZn}-\mathrm{H}]_{2}^{2+}$ containing (a) L-T or (b) D-T.

were obtained using $\left[\mathrm{T}_{2} \mathrm{Zn}\right]^{2+},[\mathrm{P}]^{+}$, and $[\mathrm{AH}]^{+}$as reference ions, respectively). The tandem mass spectra are shown in Figure 5. These results indicated that $\left[\mathrm{T}_{2} \mathrm{Zn}\right]^{2+}$ and $[\mathrm{P}]^{+}$were formed by a more facile cleavage of the complex of [TAZn-H $]_{2}^{2+}$ containing L-T. The $[\mathrm{AH}]^{+}$ion was only formed by dissociation of [TAZn$\mathrm{H}]_{2}^{2+}$ containing D-T.

The reason for the more facile or unique dissociation for the metal binding complexes remains unclear. Recently, a similar facile dissociation was found for two cis diastereomers of the glycol lesions of 2'-deoxyuridine, 5-methyl-2'-deoxycytidine, and thymidine [43]. Usually, chiral recognition is explained by a difference in stability between two diastereomeric complexes. However, in the present results this explanation is not adequate. This work demonstrates that the method depends strongly on the choice of binding ion for the chiral recognition characteristic. This result might indicate that the binding ion affects the strength of the interaction between the target and the chiral reference [44]. The influence of binding ion would be enhanced in the gas phase due to the absence of solvent. Therefore different binding ions might induce different dissociation pathways [45, 46]. However, another question remains unresolved. What is the origin of the proton in these daughter ions, i.e., $[\mathrm{P}]^{+},[\mathrm{TH}]^{+}$and $[\mathrm{AH}]^{+}$? The first possibility is that the proton comes from the amino acid or benzoic acid formed as neutral fragments in the tandem MS experiments. The second possibility is that the proton comes from an active hydrogen in $\mathrm{T}$. The existence of a relatively active hydrogen in $\mathrm{T}$ was proved by deuterium-hydrogen exchange experiments. 


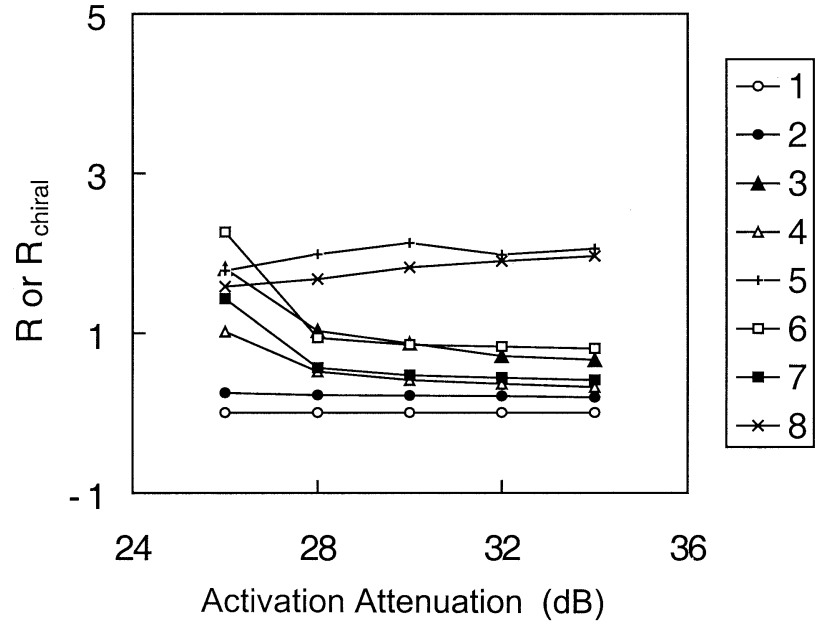

Figure 6. Effect of activation attenuation on the relative abundance ratio $\mathrm{R}$ and the chiral selectivity $\mathrm{R}_{\text {chiral }}$ using $[\mathrm{TAZn}-\mathrm{H}]_{2}^{2+}$ as parent ion. 1 and 2 denote $R_{L}$ and $R_{D}$ using $[A H]^{+}$as a reference ion, respectively; 3,4 , and 5 denote $R_{L}, R_{D}$ and $R_{\text {chiral }}$ using $\left[T_{2} Z n\right]^{2+}$ as a reference ion, respectively; 6,7 , and 8 denote $R_{L}, R_{D}$ and $\mathrm{R}_{\text {chiral }}$ using $[\mathrm{P}]^{+}$as a reference ion.

The experiment was performed by dissolving $\mathrm{T}$ and anhydrous $\mathrm{ZnSO}_{4}$ in 50:50 (vol/vol) $\mathrm{D}_{2} \mathrm{O}-\mathrm{CD}_{3} \mathrm{OD}$. Because the molecular-ion peak $(\mathrm{m} / \mathrm{z} 470)$ was not effectively detected by EI method, CI was used with acetonitrile as reaction gas. A peak of $\mathrm{m} / \mathrm{z} 473$ (deuteriumlabeled $[\mathrm{TH}]^{+}$) was detected. Consequently, this experiment demonstrated that a relatively active hydrogen exists in $\mathrm{T}$.

\section{Validation of the Method}

First, the reproducibility of the present method was investigated by changing the activation energy but maintaining the activation pulse length of $1 \mathrm{~s}$. The pair of diastereomeric complexes of $[\mathrm{TAZn}-\mathrm{H}]_{2}^{2+}$ was selected because of their strong chiral recognition ability. The experiment was performed with the sequence: $[\mathrm{TAZn}-\mathrm{H}]_{2}^{2+}$ containing D-T was first studied in an activation attenuation experiment, then $[\mathrm{TAZn}-\mathrm{H}]_{2}^{2+}$ containing L-T was studied at the same activation attenuation. The activation attenuation was then increased and the pair of diastereomeric complexes was studied in the same way. The activation attenuation was increased from $26 \mathrm{~dB}$ to $34 \mathrm{~dB}$ with an interval of 2 $\mathrm{dB}$. The effect of activation attenuation on the values of $R$ and $R_{\text {chiral }}$ is illustrated in Figure 6. It was shown that using $[\mathrm{AH}]^{+}$as a reference ion, $\mathrm{R}_{\mathrm{D}}$ remained equal to zero and $R_{L}$ changed very little over the entire activation attenuation range. In the same activation attenuation range the values of $R_{D}$ and $R_{L}$ also changed very little using $[\mathrm{P}]^{+}$or $\left[\mathrm{T}_{2} \mathrm{Zn}\right]^{2+}$ as a reference ion except for the activation attenuation of $26 \mathrm{~dB}$. Moreover the value of $R_{\text {chiral }}$ changed only over the narrow range from 1.99 to 2.13 using $\left[\mathrm{T}_{2} \mathrm{Zn}\right]^{2+}$ as a reference ion when the activation attenuation changed from 28 to $34 \mathrm{~dB}$. Using $[\mathrm{P}]^{+}$as a reference ion the value of $\mathrm{R}_{\text {chiral }}$ increased only by 0.39 when the activation attenuation changed from 26 to $34 \mathrm{~dB}$. Therefore it can be concluded that the direction of chiral recognition is not changed by the activation attenuation and the extent of chiral recognition depends only weakly on the activation attenuation.

Subsequently, the reproducibility of the present method was further investigated by continuously acquiring tandem mass spectra of $[\mathrm{TAZn}-\mathrm{H}]_{2}^{2+}$ (containing L-T) with the activation attenuation maintained at $32 \mathrm{~dB}$ and the activation pulse length maintained at $1 \mathrm{~s}$ (continuously determined six times, each with 20 accumulated scans). An average value of $R_{L}=0.71$ was determined with R.S.D. $=4.7 \%$ using $\left[\mathrm{T}_{2} \mathrm{Zn}\right]^{2+}$ as a reference ion, and an average value of $R_{L}=0.83$ was determined with R.S.D. $=4.5 \%$ using $[\mathrm{P}]^{+}$as a reference ion. These results demonstrate that the chiral recognition method has satisfactory reproducibility.

The possibility of interference by an acid was investigated by adding acetic acid $(1 \%, \mathrm{vol} / \mathrm{vol})$ to the solution mixed with $\mathrm{Zn}^{2+}$ or $\mathrm{Cu}^{2+}$, L-tryptophan, and D-T. Although the first stage mass spectra were found to be sensitive to the acid, the important peaks, i.e., $[\mathrm{TAZn}-\mathrm{H}]_{2}^{2+},[\mathrm{TACu}-\mathrm{H}]_{2}^{2+}$ and $[\mathrm{TAH}]^{+}$, were still produced. Fortunately, in the tandem mass spectra the abundance ratios were found to be rather insensitive to acetic acid.

\section{Conclusions}

The novel metal binding complexes, $[\mathrm{TAZn}-\mathrm{H}]_{2}^{2+}$ and $[\mathrm{TACu}-\mathrm{H}]_{2}^{2+}$, successfully demonstrated a high degree of chiral recognition of T. Moreover, it was proven that these novel complexes access additional dissociation pathways that provide more chiral discriminative information. Formation of the unique fragment, i.e., $[\mathrm{TH}]^{+}$or $[\mathrm{AH}]^{+}$, depended dramatically on the stereo configuration of $\mathrm{T}$. The high degree of chiral recognition was determined by discriminating the fragments formed not only by whole-molecule loss but also fractional-molecule loss. Finally, the method was shown to have good reproducibility and a strong ability to tolerate interference of acid.

\section{Acknowledgments}

This work was supported by the National Natural Science Foundation of China (no. 20175034), and by Natural Science Foundation of Shanghai (no. 00ZA14077).

\section{References}

1. Zepik, H.; Shavit, E.; Tang, M.; Jensen, T. R.; Kjaer, K.; Bolbach, G.; Leiserowitz, L.; Weissbuch, I.; Lahav, M. Chiral Amplification of Oligopeptides in Two-Dimensional Crystalline SelfAssemblies on Water. Science 2002, 295, 1266-1269.

2. Hodyss, R.; Julian, R. R.; Beauchamp, J. L. Spontaneous Chiral Separation in Noncovalent Molecular Clusters. Chirality 2001, 13, 703-706. 
3. Fales, H. M.; Wright, G. J. Detection of Chirality with the Chemical Ionization Mass Spectrometer. "Meso" Ions in the Gas Phase. J. Am. Chem. Soc. 1977, 99, 2339-2340.

4. Finn, M. G. Emerging Methods for the Rapid Determination of Enantiomeric Excess. Chirality 2002, 14, 534-540.

5. Sawada, M. Chiral Recognition Detected by Fast Atom Bombardment Mass Spectrometry. Mass Spectrom. Rev. 1997, 16, 73-90.

6. Shizuma, M.; Adachi, H.; Takai, Y.; Hayashi, M.; Tanaka, J.; Takeda, T.; Sawada, M. Combinatorial Evaluation of the Chiral Discrimination of Permethylated Carbohydrates Using Fast-Atom Bombardment Mass Spectrometry. Carbohydr. Res. 2001, 335, 275-281.

7. Reetz, M. T.; Becher, M. H.; Klein, H-W; Stöckigt, D. A Method for High-Throughput Screening of Enantioselective Catalysts. Angew. Chem. Int. Ed. 1999, 38, 1758-1761.

8. Sawada, M.; Takai, Y.; Yamada, H.; Hirayama, S.; Kaneda, T.; Tanaka, T.; Kamada, K.; Mizooku, T.; Takeuchi, S.; Ueno, K.; Hirose, K.; Tobe, Y.; Naemura, K. Chiral Recognition in Host-Guest Complexation Determined by the EnantiomerLabeled Guest Method Using Fast Atom Bombardment Mass Spectrometry. J. Am. Chem. Soc. 1995, 117, 7726-7736.

9. Sawada, M.; Takai, Y.; Yamada, H.; Nishida, J.; Kaneda, T.; Arakawa, R.; Okamoto, M.; Hirose, K.; Tanaka, T.; Naemura, K. Chiral Amino Acid Recognition Detected by Electrospray Ionization (ESI) and Fast Atom Bombardment (FAB) Mass Spectrometry (MS) Coupled with the Enantiomer-Labeled (EL) Guest Method. J. Chem. Soc. Perkin Trans. 2 1998, 3, 701-710.

10. Garcia, C.; Guyot, J.; Jeminet, G.; Emmanuelle, L. W.; Nierengarten, H.; Dorsselaer, A. V. Chiral Recognition Properties of Spiroacetal Polyethers Using Electrospray Ionization Mass Spectrometry. Tetrahedron Lett. 1999, 40, 4997-5000.

11. Sawada, M.; Shizuma, M.; Takai, Y.; Adachi, H.; Takeda, T.; Uchiyama, T. Measurement of Chiral Amino Acid Discrimination by Cyclic Oligosaccharides: A Direct FAB Mass Spectrometric Approach. Chem. Commun. 1998, 14, 1453-1454.

12. Sawada, M.; Takai, Y.; Yamada, H.; Kaneda, T.; Kamada, K.; Mizooku, T.; Hirose, K.; Tobe, Y.; Naemura, K. Chiral Recognition in Molecular Complexation for the Crown Ether-Amino Ester System. A Facile FAB Mass Spectrometric Approach. J. Chem. Soc. Chem. Commun. 1994, 21, 2497-2498.

13. Arakawa, R.; Kobayashi, M.; Ama, T. Chiral Recognition in Association Between Antimony Potassium Tartrate and Bis(Lalaninate)ethylenediamine Cobalt(III) Complexes Using Electrospray Ionization Mass Spectrometry. J. Am. Soc. Mass Spectrom. 2000, 11, 804-808.

14. Krishna, P.; Prabhakar, S.; Manoharan, M.; Jemmis, E. D.; Vairamani, M. Chiral Recognition and the Determination of Optical Purity of Some Amino Acid Ester Salts Using Monosaccharides as Chiral Selectors Under Liquid Secondary Ion Mass Spectral Conditions. Chem. Commun. 1999, 13, 12151216.

15. Diaz, D. D.; Yao, S.; Finn, M. G. Measurement of Enantiomeric Excess of Amines by Mass Spectrometry Following Kinetic Resolution with Solid-Phase Chiral Acylating Agents. Tetrahedron Lett. 2001, 42, 2617-2619.

16. Shizuma, M.; Imamura, H.; Takai, Y.; Yamada, H.; Takeda, T.; Takahashi, S.; Sawada, M. A New Reagent to Evaluate Optical Purity of Organic Amines by FAB Mass Spectrometry. Chem. Lett. 2000, 11, 1292-1293.

17. Guo, J.; Wu, J.; Siuzdak, G.; Finn, M. G. Measurement of Enantiomeric Excess by Kinetic Resolution and Mass Spectrometry. Angew. Chem. Int. Ed. 1998, 38, 1755-1758.

18. Yao, Z. P.; Wan, T. S. M.; Kwong, K. P.; Che, C. T. Chiral Recognition of Amino Acids by Electrospray Ionization Mass
Spectrometry/Mass Spectrometry. Chem. Commun. 1999, 20 2119-2120.

19. Yao, Z. P.; Wan, T. S. M.; Kwong, K. P.; Che, C. T. Chiral Analysis by Electrospray Ionization Mass Spectrometry/Mass Spectrometry. 1. Chiral Recognition of 19 Common Amino Acids. Anal. Chem. 2000, 72, 5383-5393.

20. Yao, Z. P.; Wan, T. S. M.; Kwong, K. P.; Che, C. T. Chiral Analysis by Electrospray Ionization Mass Spectrometry/Mass Spectrometry. 2. Determination of Enantiomeric Excess of Amino Acids. Anal. Chem. 2000, 72, 5394-5401.

21. Tao, W. A.; Zhang, D.; Wang, F.; Thomas, P. D.; Cooks, R. G. Kinetic Resolution of D,L-Amino Acids Based on Gas-Phase Dissociation of Copper(II) Complexes. Anal. Chem. 1999, 71, 4427-4429.

22. Tao, W. A.; Zhang, D.; Nikolaev, E. N.; Cooks, R. G. Coppe$\mathrm{r}$ (II)-Assisted Enantiomeric Analysis of D,L-Amino Acids Using the Kinetic Method: Chiral Recognition and Quantification in the Gas Phase. J. Am. Chem. Soc. 2000, 122, 10598-10609.

23. Tao, W. A.; Gozzo, F. C.; Cooks, R. G. Mass Spectrometric Quantitation of Chiral Drugs by the Kinetic Method. Anal. Chem. 2001, 73, 1692-1698.

24. Tao, W. A.; Wu, L.; Cooks, R. G.; Wang, F.; Begley, J. A.; Lampert, B. Rapid Enantiomeric Quantification of an Antiviral Nucleoside Agent (D,L-FMAU, 2'-Fluoro-5-methyl- $\beta$,D,L-arabinofuranosyluracil) by Mass Spectrometry. J. Med. Chem. 2001, 44, 3541-3544.

25. Fago, G.; Filippi, A.; Giardini, A.; Laganà, A.; Paladini, A.; Speranza, M. Chiral Recognition of $O$-Phosphoserine by Mass Spectrometry. Angew. Chem. Int. Ed. 2001, 40, 4051-4054.

26. Vékey, K.; Czira, G. Distinction of Amino Acid Enantiomers Based on the Basicity of Their Dimers. Anal. Chem. 1997, 69, 1700-1705.

27. Grigorean, G.; Ramirez, J.; Ahn, S. H.; Lebrilla, C. B. A Mass Spectrometry Method for the Determination of Enantiomeric Excess in Mixtures of D,L-Amino Acids. Anal. Chem. 2000, 72, 4275-4281.

28. Grigorean, G.; Lebrilla, C. B. Enantiomeric Analysis of Pharmaceutical Compounds by Ion/Molecule Reactions. Anal. Chem. 2001, 73, 1684-1691.

29. Deng, H.; Kebarle, P. Bond Energies of Copper Ion-Ligand L Complexes $\mathrm{CuL}_{2}^{+}$Determined in the Gas Phase by Ion-Ligand Exchange Equilibria Measurements. J. Am. Chem. Soc. 1998, 120, 2925-2931.

30. Gatlin, C. L.; Tureček, F.; Vaisar, T. Copper(II) Amino Acid Complexes in the Gas Phase. J. Am. Chem. Soc. 1995, 117, 3637-3638.

31. Gatlin, C. L.; Tureček, F.; Vaisar, T. Gas-phase Complexes of Amino Acids with $\mathrm{Cu}(\mathrm{II})$ and Diimine Ligands. Part I. Aliphatic and Aromatic Amino Acids. J. Mass Spectrom. 1995, 30, $1605-1616$

32. Gatlin, C. L.; Tureček, F.; Vaisar, T. Gas-phase Complexes of Amino Acids with $\mathrm{Cu}(\mathrm{II})$ and Diimine Ligands. Part II. Amino Acids with $\mathrm{O}, \mathrm{N}$, and S Functional Groups in the Side-chain. J. Mass Spectrom. 1995, 30, 1617-1627.

33. Cerda, B. A.; Wesdemiotis, C. The Relative Copper(I) Ion Affinities of Amino Acids in the Gas Phase. J. Am. Chem. Soc. 1995, 117, 9734-9739.

34. Augusti, D. V.; Carazza, F.; Augusti, R.; Tao, W. A.; Cooks, R. G. Quantitative Chiral Analysis of Sugars by Electrospray Ionization Tandem Mass Spectrometry Using Modified Amino Acids as Chiral Reference Compounds. Anal. Chem. 2002, 74, 3458-3462

35. Winkler, F. J.; Stahl, D.; Maquin, F. Chirality Effects in the Chemical Ionization Mass Spectra of Dialkyl Tartrates. Tetrahedron Lett. 1986, 27, 335-338. 
36. Hofmeister, G.; Leary, J. A. Chiral Recognition of LithiumCoordinated Diols Using Tandem Mass Spectrometry. Org. Mass Spectrom. 1991, 26, 811-812.

37. Winkler, F. J.; Medina, R.; Winkler, J.; Krause, H. Mass Spectral and Semiempirical Studies on Chiral Discrimination in Gaseous Aggregation Products of Protonated Dialkyl Tartrates. J. Chromatogr. A 1994, 666, 549-556.

38. Dang, T. T.; Pedersen, S. F.; Leary, J. A. Chiral Recognition in the Gas Phase: Mass Spectrometric Studies of Diastereomeric Cobalt Complexes. J. Am. Soc. Mass Spectrom. 1994, 5, 452-459.

39. Winkler, F. J.; Medina, R.; Winkler, J.; Krause, H. ChiralityDirected Self-assembly of Supramolecular Propellers of Dialkyltartrate Trimers with Hydronium, Ammonium, and Primary Aminium Ions in CI Mass Spectra. J. Mass Spectrom. 1997, 32, 1072-1079.

40. Denisov, E. V.; Shustryakov, V.; Nikolaev, E. N.; Winkler, F. J.; Medina, R. FT ICR Investigations of Chiral Supramolecular Propellers of Dialkyltartrate Trimers with Methylammonium Ions. Int. J. Mass Spectrom. 1999, 182, 357-368.

41. Nikolaev, E. N.; Denisov, E. V.; Rakov, V. S.; Futrell, J. H. Investigation of Dialkyl Tartrate Molecular Recognition in
Cluster Ions by Fourier Transform Mass Spectrometry: A Comparison of Chirality Effects in Gas and Liquid Phases. Int. J. Mass Spectrom. 1997, 167, 259-268.

42. Tao, W. A.; Wu, L. M.; Cooks, R. G. Rapid Enantiomeric Determination of $\alpha$-Hydroxy Acids by Electrospray Ionization Tandem Mass Spectrometry. Chem. Comm. 2000, 20, 2023-2024.

43. Wang, Y.; Vivekananda, S.; Zhang, K. ESI-MS/MS for the Differentiation of Diastereomeric Pyrimidine Glycols in Mononucleosides. Anal. Chem. 2002, 74, 4505-4512.

44. Paladini, A.; Calcagni, C.; Dipalma, T.; Speranza, M.; Lagana, A.; Fago, G.; Filippi, A.; Satta, M.; Guidoni, A. G. Enantiodiscrimination of Chiral $\alpha$-Aminophosphonic Acids by Mass Spectrometry. Chirality 2001, 13, 707-711.

45. Alvarez, E. J.; Vartanian, V. H.; Brodbelt, J. S. Metal Complexation Reactions of Quinolone Antibiotics in a Quadrupole Ion Trap. Anal. Chem. 1997, 69, 1147-1155.

46. Alvarez, E. J.; Brodbelt, J. S. Evaluation of Metal Complexation as an Alternative to Protonation for Electrospray Ionization of Pharmaceutical Compounds. J. Am. Soc. Mass Spectrom. 1998, 9, 463-472. 